\title{
REALISMOS AUDIOVISUAIS: VISIBILIDADES INTERTEXTUAIS EM DOCUMENTÁRIOS TELEVISIVOS
}

\author{
Rosana de Lima Soares *
}

Resumo: $\mathrm{O}$ artigo tem como objetivo o estudo de discursos das mídias de caráter realista a fim de estabelecer uma análise contrastiva entre eles. Buscaremos demonstrar que o estabelecimento das fronteiras entre fato e relato se faz no tensionamento dessas posições, alargando os limites entre "referencialidade" e "ficcionalidade" em narrativas audiovisuais, contribuindo para a reflexão sobre o estatuto da imagem na atualidade. Fatos e relatos colocam-se, assim, como estratégias complementares na organização desses discursos, embaralhando as fronteiras entre realidade e fabulação. Por meio da análise do documentário televisivo "Make Bradford British", exibido pelo canal inglês Channel Four, exploramos a questão dos novos realismos presentes nos discursos das mídias a partir da observação dos modos de construção da representação de diferentes sujeitos nas mídias.

Palavras-chave: Documentário. Televisão. Políticas da representação. Reality TV. Estigmas sociais.

Resumen: Este artículo tiene como objetivo estudiar los discursos de los medios de carácter realista con el fin de establecer un análisis contrastivo entre ellos. Intentaremos demostrar que el establecimiento de las fronteras entre hecho y relato se hace en el tensionamiento de esas posiciones, ampliando los límites entre "referencialidad" y "ficcionalidad" en las narraciones audiovisuales y contribuyendo a la reflexión sobre el estatuto de la imagen en la actualidad. Hechos y relatos se presentan, así, como estrategias complementarias en la organización de estos discursos, enmarañando las fronteras entre realidad y fabulación. A través del análisis documental televisivo Make Bradford British, exhibido por el canal inglés Channel Four, exploramos la cuestión de los nuevos realismos presentes en los discursos de los medios a partir de la observación de los modos de construcción de la representación de diferentes sujetos en los medios de comunicación.

Palabras clave: documental, televisión, políticas de representación, reality $t v$, estigmas sociales.

Abstract: This research aims to study media discourses which convey a realistic approach in order to perform a contrastive analysis between them, pointing out proximities and differences. As one of my research hypothesis I intend to demonstrate that the limits between fact and reality occur at the very tensioning of their assumed grounds. New realisms are established in audiovisual narratives broadening the boundaries between "referentiality" and "fictionality", thus contributing to the debate on the contemporary statute of images. Through the analysis of the British television documentary "Make Bradford British" (Channel Four), I intend to report on the issue of new realisms identified

\footnotetext{
${ }^{*}$ Universidad de São Paulo, ECA - Escola de Comunicação e Artes, Programa de Pósgraduação em Meios e Processos Audiovisuais. 05508-020, São Paulo, Brasil. Email: rosanasoares@gmail.com
}

Submissão do artigo: 28 de junho de 2015. Notificação de aceitação: 20 de agosto de 2015. 
on media discourses today recurring to a historical perspective on the modes of addressing the concrete world. stigmas.

Key words: documentary, television, politics of representation, reality tv, social

Résumé: Cet article vise à étudier les discours du caractère réaliste des médias afin d'établir une analyse contrastée entre eux. Nous cherchons à démontrer que l'établissement de la frontière entre le fait et sa relation se fait jour dans la mise en tension de ces pôles, repoussant les limites entre «référentialité» et «fictionnel» dans les récits audiovisuels, et contribue à la réflexion sur le statut de l'image aujourd'hui. Faits et histoires sontse trouvent ainsi disposés, comme des stratégies complémentaires dans l'organisation de ces discours, brouillant les lignes entre réalité et fabulation. Grâce à l'analyse du documentaire de télévision "Make Bradford British" (Rendre Bradford britannique), diffusé sur Channel Four, nous explorons la question du nouveau réalisme du discours des médias, à partir de l'observation dans ceux-ci des modes de construction et de représentation des différents sujets.

Mots-clés: documentaires, la télévision, la représentation politique, Télé-réalité, stigmates sociaux.

$\mathrm{O}$ artigo tem como objetivo o estudo de discursos das mídias de caráter realista a fim de estabelecer uma análise contrastiva entre eles. Buscaremos demonstrar que o estabelecimento das fronteiras entre fato e relato se faz no tensionamento dessas posições, alargando os limites entre "referencialidade" e "ficcionalidade" em narrativas audiovisuais, contribuindo para a reflexão sobre o estatuto da imagem na atualidade. Fatos e relatos colocam-se, assim, como estratégias complementares na organização desses discursos, embaralhando as fronteiras entre realidade e fabulação. Por meio da observação de documentários e reportagens, exploramos a questão dos novos realismos presentes nos discursos das mídias a partir de uma perspectiva histórica sobre as formas de endereçamento do mundo concreto, passando pelas injunções das imagens técnicas frente a uma cultura audiovisual cada vez mais marcada por processos que visam produzir determinados efeitos de realidade, oscilando entre o retorno do real e o elogio da ficção. 
Tomamos a expressão "novos realismos" a partir da definição de Jaguaribe, que aponta no cinema iraniano, no manifesto do grupo escandinavo Dogma, no cinema engajado britânico, nos documentários contemporâneos, em filmes latino-americanos sobre conflitos urbanos, entre outros exemplos, os "novos registros do realismo" como um fenômeno global - presentes não apenas no cinema, mas também na literatura, na fotografia e nas mídias - que contribui para os modos de percepção da realidade: "No Brasil, os novos realismos despontam dentro de gêneros como o romance policial e a narrativa da violência marginal, ou em retratos do cotidiano que esmiúçam, com maior ou menor pendor psicológico ou naturalista, os impasses de vidas anônimas" (Jaguaribe, 2007:11).

Sabemos ser este um tema abrangente e, desse modo, iremos nos deter em exemplos recentes voltados à construção da representação de diferentes sujeitos nas mídias. Buscamos identificar, nas imagens, as maneiras pelas quais se estabelecem os espaços de visibilidade/invisibilidade em relação a grupos minoritários estigmatizados no cenário social. Nas oscilações entre reforço ou transposição de estigmas, tais narrativas audiovisuais empreendem, em relação ao "outro" para o qual se voltam, processos de assujeitamento ou, ao contrário, de protagonismo. Nesse confronto de representações, para além de visões hegemônicas, uma pergunta norteia a proposta: se as realidades são discursivamente construídas, como propor modos de representação do "outro" da forma mais ativa (e altiva) possível?

Ao apontar que, recentemente, as contradições sociais têm sido tematizadas, na produção teórica e audiovisual contemporânea, por meio das relações entre estética e política, Figueiredo nos alerta: "Se, no passado, ao fazer referência ao abismo entre as elites e o povo, falava-se dos que tinham ou não tinham voz, hoje, fala-se, cada vez mais, dos que possuem ou não possuem visibilidade" (Figueiredo, 2012: 11). Mais do que a proliferação de imagens ou o excesso de exposição, "é a imagem mais do que a palavra, o 
espectador, mais do que o ouvinte ou o leitor, que servem de ponto de partida quando se trata de refletir sobre a necessidade de alterar a distribuição de papéis e competências hierarquicamente estabelecidos" (Figueiredo, 2012: 11), fato que nos coloca frente às especificidades da cultura audiovisual contemporânea, sobre a qual iremos refletir em alguns de seus aspectos.

Desse modo, a estética realista e a hiper-realidade; a retórica testemunhal e a ênfase em visualidades precárias; as políticas de partilha do sensível e os novos regimes de visibilidade, entre outros, são elementos fundamentais para problematizarmos o estatuto das imagens hoje. A dimensão da cultura, e os processos de sua legitimação por meio dos discursos circulantes, possibilita que pensemos a produção audiovisual como sintoma de uma época pautada pelo desajuste, pelo transbordamento e pelo conflito, aspectos que se fazem presentes, portanto, em tal produção.

Ao nos indagarmos sobre as maneiras pelas quais a autenticação da realidade se impõe nas narrativas da televisão e do cinema, indagamo-nos, também, sobre as possibilidades de delinear os contornos de um realismo crítico e político, oscilando entre uma forma documental de expressividade e o melodrama ficcional narrativo. Para além da construção de efeitos de realidade, em que ocorre o mascaramento dos processos de ficcionalização nela implicados, vemos nas narrativas audiovisuais uma espécie de retorno pregnante do real (na forma de choque, paixão ou horror) ${ }^{1}$ contrapondo-se ao elogio disperso da ficção (na encenação reiterada do mundo vivido). ${ }^{2}$

\footnotetext{
${ }^{1}$ A exemplo do que apontam diversos teóricos, as narrativas audiovisuais contemporâneas se constituem por meio de inúmeros hibridismos e, mais do que isso, a partir de uma reiteração da possibilidade de representação fiel (ou verdadeira) da realidade. A expressão "choque do real", cunhada por Beatriz Jaguaribe em livro homônimo, é por ela definida como sendo "a utilização de estéticas realistas visando suscitar um efeito de espanto catártico no leitor ou espectador" (Jaguaribe, 2007: 100). Para a autora, o impacto do "choque" não vem de seu caráter extraordinário, mas de sua intensificação. Ainda nesse sentido, a "paixão pelo real" (em expressão de Badiou, 2002), ou o "retorno do real" (nas palavras de Foster, 1999), fazem-se presentes em diversos discursos das mídias, de modo especial na televisão e no cinema, sinalizando a presença marcante de elementos de
} 
Se, a partir da psicanálise, o Real é aquilo que insiste, mas não resiste à simbolização, é no registro do imaginário que podemos investigar as atuais políticas de construção da representação frente às posições de totalização ou inadequação, adesão ou fricção, transparência ou opacidade, presentes nas narrativas audiovisuais, pensadas não como categorias estanques, mas como formas genéricas: "Contra a ficção que pretende existir por si mesma, como reflexo do real, é proposto o discurso que fala sobre suas próprias condições de existência e, portanto, afirma-se como reflexo do trabalho de produção e de suas funções sociais e materiais" (Xavier, 1984: 134). Assim como a opacidade permite que seja desvelado o dispositivo, ao negar a transparência do discurso audiovisual provoca o tensionamento dessas posições, apontando para outros modos de dar a ver o visível.

Ao voltarmo-nos para os modos de construção da realidade em narrativas audiovisuais assumimos, portanto, que processos de ficcionalização se fazem presentes para o engendramento da referencialidade pretendida em tais discursos, tanto no caso de produções de caráter factual, como naquelas propriamente ficcionais. Nas palavras de Jaguaribe, "o paradoxo do realismo consiste em inventar ficções que parecem realidades" (Jaguaribe, 2007: 16). Mais do que isso, desde a modernidade compreende-se que as realidades são socialmente fabricadas, ou seja, "que os imaginários culturais são parte da realidade e que nosso

realismo/naturalismo ou delineando o "deserto do real" e seu potencial catártico (como afirma Zizek, 2002).

${ }^{2}$ Nesse sentido, lembramos a obra de Wolfgang Iser, especialmente no que diz respeito ao princípio da representação, em que o realismo seria, também ele, fictício ou imaginário pois estes se apresentam como "disposições antropológicas" com poder libertário em relação às normas culturais estabelecidas (Iser, 2013). A obra de Umberto Eco, especialmente ao tratar dos conceitos de autor e leitor modelos (ou implícitos), aproxima-se de Iser em sua dimensão da recepção como um modo ativo de participação (Eco, 1994). Além desses autores, Peter Gay, aponta os modos diversos de endereçamento da realidade em obras de ficção, notadamente naquelas de cunho predominantemente realista (Gay, 2010). 
acesso ao real e à realidade somente se processa por meio de representações, narrativas e imagens" (Jaguaribe, 2007: 16).

Interessa-nos, assim, explorar as tensões advindas dessa relação e seus modos de inscrição nos discursos das mídias, produzindo efeitos de sentido que vão da ilusão da objetividade ao testemunho da verdade em tais narrativas (cf. Soares; Freire, 2013). É importante destacar que, na passagem do fato ao relato, um processo de narrativização se inscreve nos discursos referenciais, no qual determinadas formas narrativas contribuem para produzir efeitos de sentido que corroboram seus pressupostos, ou seja: "Só podemos conhecer o real comparando-o ou equiparando-o ao imaginável" (White, 1994: 115).

Do ponto de vista metodológico, buscamos abordar os novos realismos por meio da temática dos estigmas sociais presentes em narrativas audiovisuais. Ao falarmos de mídias e estigmas partimos de alguns postulados. $\mathrm{O}$ primeiro diz respeito à dinâmica dos processos de identificação; o segundo diz respeito aos discursos referenciais a partir da assunção de seu estatuto enquanto construção na linguagem, lembrando o caráter arqueológico dessa criação; o terceiro diz respeito à definição de discurso sob três aspectos: a) a linguagem é constituinte do humano; b) o mundo vivido é instaurado pela linguagem; c) o discurso é um laço social que se desenvolve na linguagem. Nas diferentes posições ocupadas pelos sujeitos no tecido social; nos embates entre cada um e todos os outros; nas demarcações entre estigmas, estereótipos e preconceitos; nos modos de estabelecimento dos espaços de visibilidade e invisibilidade social; e nas disputas por formas hegemônicas de construção da representação nos discursos circulantes, identificamos um terreno fértil para a problematização de tal questão. Se o retorno do real surge como resposta ao elogio da ficção, novos realismos parecem também apontar para novos modos de ficcionalização. 
A produção televisual recente, notadamente documentários, grandes reportagens e reality shows (estes últimos considerados não enquanto programas isolados, mas como um gênero televisivo que se espraia por diversos outros gêneros) constitui a amostragem ampliada da proposta. Nesse sentido, destacamos as produções integrantes daquilo que se convencionou chamar de "reality tv" (ou "factual tv", incluindo documentários jornalísticos), do qual fazem parte não apenas reality shows, mas também documentários, séries, seriados, reportagens, programas de auditório ou de variedades, enfim, uma imensa gama de gêneros e formatos que confluem para este que seria, a partir de nossas observações, o modo privilegiado presente na televisão atual (cf. Machado; Vélez, 2009; Kavka, 2012).

A partir da observação da programação televisiva e da aderência aos reality shows - tanto do lado da produção, como da recepção -, notamos que, ao contrário do que acontecia anteriormente, as formas de inscrição da realidade na televisão tem se pautado por novos realismos. Nesse sentido, a realidade é encenada através de diferentes formas narrativas oriundas da ficção. A reality tv torna-se a narrativa televisiva predominante, para além dos reality shows, como se os gêneros televisivos se endereçassem de algum modo a ela. Essa demarcação é tomada como uma espécie de marca distintiva (ou até mesmo uma vocação da produção televisiva), apontando sua inserção na produção audiovisual recente.

Ao observarmos os programas televisivos, tomamos como ponto de partida formas narrativas impuras, que privilegiam a referencialidade mas englobam estratégias de ficcionalização. Para alcançar nosso intuito, estabelecemos nesse momento diálogos com a produção inglesa, buscando demonstrar como as questões dos hibridismos e dos novos realismos se apresentam em diferentes culturas, enfatizando os conceitos articuladores das análises. Desse modo, buscamos tratar não apenas de um dos grandes eixos no estudo das imagens hoje, mas também iluminar, ainda que de modo 
tangencial, a dinâmica da produção audiovisual, em que as especificidades nos modos de produção, circulação e recepção tornam singulares seus diferentes discursos, dentre os quais destacamos a televisão.

Em termos conceituais, finalmente, observamos os espaços da presença/ausência de atores sociais não hegemônicos, bem como os pontos de redundâncias e ressonâncias dos estigmas sociais nos discursos das mídias; as formações discursivas como espaços de intertextualidade e heterogeneidade, comumente referidas nos debates sobre convergências midiáticas e hibridismos narrativos; as novas posicionalidades do sujeito em meio à proliferação de imagens e, consequentemente, as transformações no imaginário social; as políticas de representação ou as atuais formas de "partilha do sensível” (cf. Rancière, 2005), especialmente aquelas relacionadas a figuras de alteridade, estabelecendo as tensões entre as narrativas do mesmo e do outro nelas apresentadas (Prado, 2008).

Em relação à amostragem, interessam-nos os "contratos comunicacionais" (ou "pactos de leitura") frente aos novos "regimes de visibilidade" em que os discursos referenciais ${ }^{3}$ deslizam para narrativas híbridas presentes nas mídias por meio de novos realismos: "Para nós que discutimos os regimes de visibilidade dos media, construídos em torno dos contratos de comunicação voltados a modalizar formas de ser e de fazer o corpo e com o corpo, sustentando-se em valores simbólicos ligados ao mundo do consumo, tais formas de ver e de ser olhados pelos objetos culturais é preciosa" (Prado, 2012: 181). Desse modo, reportagens e documentários não são considerados de maneira estanque, ressaltando as interfaces entre referencialidade e ficcionalidade presentes na televisão e no cinema.

\footnotetext{
${ }^{3}$ Discursos voltados à experiência da realidade, em que elementos históricos são tomados de forma supostamente objetiva para compor os relatos sobre os fatos, ao contrário do que é suposto nos discursos ficcionais, em que modos de fabulação são prioritariamente acionados na composição de suas narrativas (ver Barthes, 1988).
} 
Assumindo, portanto, o hiato desde sempre incontornável entre linguagem e referente, e embasados pelos debates sobre convergências midiáticas e hibridismos discursivos, vislumbramos um conjunto de imagens que oscila entre as fronteiras movediças das narrativas impuras, mescladas por meio do trânsito entre elementos estéticos e tecnológicos. A crítica ao conceito de representação e sua desconstrução, como apontamos no início do artigo, é um importante eixo teórico-metodológico para as análises, problematizando tensionando narrativas de caráter referencial a partir dos modos de "dar a ver" as figuras de alteridade nelas presentes e as políticas de representação nelas ensaiados. Entendemos "política" na acepção dada por Rancière a este conceito: "A atividade política é a que desloca um corpo do lugar que lhe era designado ou muda a destinação de um lugar; ela faz ver o que não cabia ser visto, faz ouvir como discurso o que só era ouvido como barulho", alterando, assim, os regimes de visibilidade (Rancière, 1996: 42).

Dentro desse cenário, a questão dos modos de construção da representação - especialmente de sujeitos tradicionalmente deles excluídos - pode ser elaborada a partir de alguns apontamentos, em que os discursos (ou seus vestígios) articulam-se, inicialmente, a partir da aproximação a um outro diverso e distante. Vemos surgir nessas narrativas um outro não representável e que, ao longo delas, oscila entre ausência e presença, invisibilidade e visibilidade. Em termos de posições discursivas, podemos afirmar que o outro, qualquer que seja ele, pontua desdobramentos que vão dos não ditos à inclusão consentida para, finalmente, assumir lugar de protagonismo, apontando para momentos de afirmação e identificação. Nas palavras de Geertz, ao tratar das relações entre aqueles que podem propor modos de representar o outro e aqueles neles representados, "o fim do colonialismo alterou radicalmente a natureza das relações sociais entre os que perguntam e observam e os que são perguntados e observados" (cf. Geertz, 2005: 172), problematizando os relatos produzidos sobre os outros, 
próximos ou distantes, e acentuando o caráter conflituoso desse encontro com a alteridade.

Pensemos na proposição de Hall a respeito de identidades desalojadas de tempos, lugares e tradições específicos, identidades que parecem "flutuar livremente" (Hall, 2000: 75) no contexto de uma vida social globalizada em seus estilos, com participação ativa dos sistemas de comunicação interligados e das imagens da mídia. Desse modo, podemos afirmar que o "outro" opera de modo relacional com o "mesmo"; incomoda justamente quando se torna mais semelhante a este. A questão dos estigmas sociais, por exemplo, aponta para esse aspecto: diferentemente dos preconceitos, eles dizem respeito ao outro que se torna próximo quando, ao contrário, deveria permanecer "em seu lugar", não encontrando, por isso, espaço nos discursos circulantes. De acordo com Charaudeau, "o discurso circulante é uma soma empírica de enunciados com visada definicional sobre o que são os seres, as ações, os acontecimentos, suas características, seus comportamentos e os julgamentos a eles ligados" (Charaudeau, 2006: 118).

As polêmicas passagens que envolvem as formações discursivas não surgem, portanto, do exterior, mas presumem a partilha do mesmo campo discursivo e das normas a ele associadas. Se o discurso constrói, em um mesmo movimento, sua identidade e sua relação com outros discursos, verdade e ficção se entrelaçam em tramas complexas, possibilitando caminhos nos quais tecer as narrativas audiovisuais.

\section{Representações da (in)visibilidade em narrativas audiovisuais}

A produção televisiva inglesa é amplamente reconhecida por meio da rede de televisão inglesa BBC - British Broadcasting Corporation -, uma emissora pública do Reino Unido fundada em 1922. Regulamentada pelo Estado, produz um grande e variado volume de programas, por meio de 
diversas estações de rádio e canais de televisão, atuando tanto em nível nacional como internacional. Tradicionalmente tida como produtora de programas de qualidade, tanto no rádio como na televisão, a BBC tem atuado na criação e renovação de gêneros audiovisuais, contribuindo para o estabelecimento de modos inovadores de fazer televisão, tanto em termos narrativos como estéticos. De formato único, combinando um modelo de gestão pública e estatal, nos últimos anos a emissora tem passado por crescentes transformações, especialmente após a entrada, no mercado britânico, de emissoras privadas, entre elas o Channel Four Television Corporation, criado em 1982 por um ato do Parlamento Britânico. Em termos de audiência, a rede é a quarta maior emissora de televisão do Reino Unido, atrás apenas da ITV (uma emissora comercial), da BBC One e da BBC Two. A exemplo de outras emissoras britânicas, por ser uma empresa de serviço público o Channel Four deve exibir conteúdo diversificado e de qualidade, ainda que não receba, como a BBC, financiamento público.

Notemos, curiosamente, que ao contrário do que ocorre em canais brasileiros a categoria reality shows não é encontrada separadamente nos sites da $\mathrm{BBC}^{4}$ ou do Channel Four ${ }^{5}$ (entre as seções, temos "drama", “comédia", "entretenimento" e "factual"), sinalizando uma importante questão, qual seja: a de que em um dos países mais destacados na produção televisiva, tal formato está espraiado em vários outros, confirmando uma das hipóteses. Da vasta produção televisiva inglesa iremos nos deter, portanto, na programação factual, termo utilizado no site das emissoras citadas ou, de modo mais abrangente, na chamada reality $t v$, destacando sua originalidade: ao percebermos o alcance da "telerrealidade" para além de seu formato mais direto (os reality shows) podemos afirmar que, longe de se caracterizar como um gênero específico, a reality tv surge, no atual

\footnotetext{
${ }^{4}$ Disponível em: www.bbc.com.

${ }^{5}$ Disponível em: www.channel4.com.
} 
momento, como o próprio modo de operação da televisão, notadamente na Inglaterra. ${ }^{6}$

A fim de demonstrar essa premissa e as linhas principais de sua observação, iremos tecer algumas considerações sobre o programa "Make Bradford British", ${ }^{7}$ documentário televisivo ${ }^{8}$ que mescla elementos de grandes reportagens, programas de entrevistas e reality shows. Lembramos, nesse momento, a importância que os gêneros factuais possuem tradicionalmente na televisão britânica, apontando para uma realidade bastante específica e instigante: a grande produção de documentários televisivos sem pensá-los de modo reducionista, colocando-os lado a lado com séries, seriados, reportagens, telejornais e realities. A pregnância das formas narrativas definidoras da reality tv é preponderante, contando com bastante aceitação não apenas por parte da audiência, mas também de produtores e realizadores. Desse modo, a maior ênfase na produção de teledramaturgia por meio de séries, seriados e novelas, além de reality shows propriamente ditos, é uma característica que perpassa a programação inglesa, confirmando também a tendência na produção de documentários e reportagens com estratégias ficcionais em suas narrativas.

Nesse ponto, uma importante característica da produção televisiva britânica se sobressai: o hibridismo de gêneros se faz de diversos modos, tanto em termos estilísticos, como tecnológicos. As fronteiras entre sensacionalismo, entretenimento, documentário e informação não estão claramente demarcadas, pois o que observamos é a presença crescente de

\footnotetext{
${ }^{6}$ Uma vasta bibliografia sobre o tema tem sido produzida por estudiosos de televisão, dentre eles destacamos: Holmes, S. \& Jermyn, D. (eds.) (2004). Understanding reality television. New York: Routledge; Murray, S. \& Ouellette, L. (eds.). (2004). Reality TV: remaking television culture. New York: New York University Press; Hill, A. (2005). Reality TV: audiences and popular factual television. New York: Routledge; Ouellette, L. (ed.) (2014). A companion to reality tv. Oxford: John Wiley \& Sons.

${ }^{7}$ Informações detalhadas em: www.channel4.com/programmes/make-bradford-british.

${ }^{8}$ Adotamos a terminologia utilizada pelo diretor, condizente com a visada inglesa, ainda que, nos estudos de televisão no Brasil, o programa provavelmente seria chamado de "série televisiva".
} 
programas que utilizam, em diferentes graus, esses elementos. Talvez a combinação de aspectos factuais e ficcionais seja justamente aquela que propicia a estruturação de um padrão de programação baseado no que estamos chamando de reality $t v$. No caso do Reino Unido, a diversidade étnica e cultural coloca em primeiro plano problemas relacionados ao multiculturalismo, imigração, xenofobia e segregação racial, temática na qual se insere o documentário televisivo "Make Bradford British", desenvolvido para o Channel Four em $2012^{9}$ e dirigido por Heenan Bhatti, ${ }^{10}$ realizador que produziu filmes, séries e documentários (como diretor e roteirista), além de atuar, anteriormente, como repórter para jornais e telejornais.

O programa contou com a participação de oito personagens, que foram agrupados em duplas compostas por pessoas com formações culturais bastante distintas para que cada um pudesse viver a vida do outro no cotidiano, dividindo com ele o mesmo espaço. Diferenças étnicas, raciais, geracionais, educacionais, profissionais, regionais, de gêneros, religiosas, culturais, políticas e econômicas foram ressaltadas para que os participantes pudessem pensar sobre as vantagens e desvantagens de se viver mais próximos ou distantes de pessoas radicalmente distintas deles mesmos, enfrentando os conflitos decorrentes desse convívio. Na maior parte, os

\footnotetext{
${ }^{9} \mathrm{O}$ documentário televisivo, composto de duas temporadas, foi realizado em quatro meses e produzido em um ano, contando com aproximadamente cem horas de gravação por episódio e sete semanas de edição. Cada episódio custou por volta de 150 mil libras, valor elevado mesmo se comparado àqueles relativos a um capítulo de uma telenovela da Rede Globo, e pouco frequente, no caso brasileiro, em outros formatos televisivos dramatúrgicos ou informativos. Bradford foi escolhida por ser uma das cidades consideradas mais segregadas no Reino Unido. Em 2014, uma outra temporada, chamada Make Leicester British, foi produzida nos mesmos moldes e com a mesma equipe, reunindo quatro participantes ingleses e quatro imigrantes de países diversos (três de países europeus e um da Somália) para tratar questões relativas à imigração e identidade, tema recorrente no debate sobre países europeus. Ver: http://www.channel4.com/programmes/make-leicesterbritish.

${ }^{10}$ Em nossa pesquisa de pós-doutorado, tivemos a oportunidade de acompanhar uma palestra e realizar uma entrevista com o diretor, além de assistir ao making of e a alguns episódios do programa, na Birmingham City University (Inglaterra), em 28 de novembro de 2013.
} 
embates foram travados em torno de questões raciais e étnicas, justamente em um programa que busca tematizar o multiculturalismo presente na sociedade britânica. Preconceito racial contra de brancos para negros, entre mulheres cristãs ou muçulmanas, entre brancos e muçulmanos, e mesmo divergências religiosas entre muçulmanos foram algumas das situações retratadas nos episódios a partir de duplas de personagens.

É assim que Rashid (37 anos, ex-jogador de rúgbi e pertencente à comunidade árabe), Maura (66 anos, juíza aposentada e moradora de um dos bairros mais ricos da cidade), Mohammad (41 anos, motorista de táxi de origem árabe), Jens (71 anos, policial aposentado e morador de uma região predominantemente formada por moradores brancos), Audrey (48 anos, mãe de três filhos e gerente de um pub), Sabbiyah (22 anos, muçulmana de origem paquistanesa nascida na Inglaterra e formada em filosofia e política), Damon (24 anos, metalúrgico e morador de um bairro em que 90\% dos moradores são brancos), Desmond (47 anos, trabalhador em serviço de limpeza e um dos poucos negros a morar em um bairro branco) se encontram e iniciam seu convívio com situações diversas das suas. Alguns dos momentos que demonstram as dificuldades dessa experiência se deram, justamente quando Rashid insistentemente paralisava sua participação no programa para suas orações cinco vezes ao dia, ou no desconforto de Sabbiyah ao trabalhar no pub gerenciado por Audrey.

Em sua entrevista, Bhatti afirmou que define seus trabalhos a partir de uma inquietação: quais são as histórias que valem a pena ser contadas e qual a melhor forma de fazer isso? Cada história, segundo ele, é singular e deve ser destacada dentre outras, seja em formato cinematográfico ou televisivo. No caso da televisão, o menor tempo de produção pode determinar alguns dos resultados, mas os assuntos voltados a atualidades, seja em forma de notícias ou reportagens, encontram mais espaço nessa mídia. Tradicionalmente, os documentários televisivos têm se dedicado a temas culturais, enfatizando a importância em narrar histórias de diferentes 
atores sociais e buscando a melhor maneira de contar essas histórias por meio de personagens fortes. Um aspecto importante foi ressaltado pelo diretor ao afirmar que há diferentes maneiras de se filmar uma história, inclusive em termos de escolhas narrativas e de gêneros, mas que atualmente é possível realizar narrativas hibridizadas e que misturem, inclusive, entretenimento e informação visando apresentar ao público a maior variedade possível de temas históricos, culturais, sociais e políticos.

Buscando agregar um grupo de pessoas que pudesse representar, de modo abrangente, aspectos multiculturais presentes em diversas regiões do Reino Unido - reproduzindo uma espécie de microcosmos com indivíduos variados - e que, ao mesmo tempo, fosse capaz de compreender as diferentes comunidades constituintes da sociedade britânica e da cidade retratada, o programa visava construir seus personagens da maneira mais aprofundada possível. Para definir os oito participantes, partiu-se de candidatos que não haviam passado em um exame de cidadania aplicado pela imigração britânica. A seleção se mostrou bastante complexa por ser, na opinião da equipe de produção, a chave definidora do programa, já que este deveria falar sobre sujeitos diversos e a posição que cada um deles ocupa na sociedade britânica. Encontrar boas histórias em comunidades de diferentes origens étnicas e culturais seria possível, segundo Bhatti, apenas se os produtores conseguissem criar bons personagens a partir dos participantes escolhidos, capazes de ao mesmo tempo entreter, cativar e desafiar a audiência.

De modo semelhante a alguns documentaristas brasileiros, entre eles Eduardo Coutinho, a passagem do indivíduo concreto ao personagem - e a naturalidade com que atores não-profissionais poderiam interpretar papéis que representassem a eles mesmos - foi um dos desafios apontados pelo diretor: "A respeito da relação entre pessoa e personagem ocorre algo interessante. Se a filmo durante uma hora, ficam na edição final cinco ou sete minutos. Faço dela um concentrado daquilo que eu acho que é o melhor 
que ela possa ter" (Coutinho, 2014: 175). Além disso, a questão da edição foi colocada com um dos pontos fundamentais da produção, já que tanto a narrativa como os personagens, de acordo com Bhatti, foram construídos no momento da montagem. Muitas vezes um personagem pode parecer excelente no momento da filmagem e, ao chegar o momento da edição das imagens, sua presença se dilui em detrimento de outro.

Nesse ponto é interessante apontar um aspecto inusitado ao pensarmos as produções televisivas britânicas e brasileiras: enquanto no Reino Unido o modelo de produção televisiva parece acompanhar aquele da produção documental (inclusive com a forte presença de documentários televisivos), no Brasil ocorre algo oposto, afastando a televisão da estética documental. No caso brasileiro, tradicionalmente a televisão (incluindo séries, reportagens ou novelas, com pequena presença de documentários) tem utilizado procedimentos de produção bastante distintos daqueles utilizados nos documentários, fato que podemos observar ao nos debruçarmos sobre entrevistas, depoimentos e relatos de realizadores, diretores e roteiristas. De modo análogo, a própria definição de "documentário" parece ser mais ampla no Reino Unido, podendo contemplar vários formatos neste gênero, incluindo educacionais, reflexivos, científicos, tradicionais, ficcionais, jornalísticos e até mesmo, como mostrado, produções seriadas.

Isso aponta para uma questão fundamental: para além da distinção entre jornalismo e cinema, ou entre reportagens e documentários, tratandoos como gêneros ou formatos separados, interessa-nos ressaltar seus pontos de contato, suas zonas de aproximação e seus espaços limítrofes, justamente pensados em produções hibridizadas em termos de discursos audiovisuais e seus efeitos de sentido (cf. Nichols, 1991; Winston, 2005). É importante sublinhar, nesse sentido, a preocupação da produção do documentário televisivo no que diz respeito à relação dos gêneros integrantes da chamada "telerrealidade" com a realidade concreta - e lembramos uma vez mais que 
o diretor, em momento algum, define seu documentário como reality show, mas concebe-o simplesmente como um documentário.

Assim como nos documentários que visam a construção do outro de modo relacional e reversível, subvertendo as posições hierarquizadas entre realizador e entrevistado, o programa analisado não se preocupa com o maior ou menor grau de verdade nele presente, mas com a construção dos personagens feita por meio da filmagem e da montagem. Mais do que se perguntar sobre se as situações criadas são artificiais ou verídicas, ou se aconteceram de fato da maneira como são mostradas, o documentário ressalta justamente seu aspecto narrativo e a fabulação implicada em sua fatura, qual seja, a de que tanto os personagens como a história emergem do processo de interação entre cada um deles e o próprio realizador, mediados pelos dispositivos estéticos, políticos, éticos e tecnológicos presentes em qualquer produção audiovisual.

A exemplo de outros realities televisivos, esse documentário - e notamos uma distinção importante em relação à televisão brasileira, já que, como dissemos, o programa não foi simplesmente classificado como uma serie, tampouco como um reality show -, ao contrário de apresentar desafios de transformação, talentos ou competição, propôs a convivência entre diferentes sujeitos em um mesmo espaço físico, caracterizando-se como uma espécie de "experimento" ou, de modo mais extenso, possibilitando uma aproximação à questão dos conflitos e intolerâncias decorrentes do convívio entre todos ${ }^{11}$. Indagado sobre a existência ou não de uma hipótese prévia à realização do programa, Bhatti afirmou não partir de uma tese que

\footnotetext{
11 Ainda que o programa tenha buscado tratar da questão multicultural como um modo de integração e não de separatismo, alguns setores da sociedade protestaram contra sua veemência em termos de crítica social. A pergunta colocada pelo diretor na apresentação do programa parece guiar sua narrativa: "How do we, despite class, cultural and religious differences, find a way to live together? What makes us all British today?". Por meio dos personagens e de seus conflitos, vemos possíveis respostas a essa questão, inserindo a televisão como agente no debate público sobre questões sociais. O mesmo ocorreu na temporada filmada em Leicester. Para mais informações, ver: www.channel4.com/programmes/make-bradford-british/articles.
} 
devesse ser comprovada mas, ao contrário, possuir apenas uma premissa. Tomando como base o multiculturalismo formador da atual sociedade britânica e problematizando o senso comum de que, para ser seu cidadão, um estrangeiro deve ser capaz de passar em um teste que prove o quão britânico ele é, o documentário televisivo partiu de duas perguntas: o que faz de alguém um britânico? O que é comum a todos os britânicos? As questões se referem a um tema especifico mas dizem respeito a aspectos mais gerais sobre como tratar temáticas densas e socialmente relevantes de modo reflexivo e, ao mesmo tempo, atraente.

Nesse sentido, destacamos tanto na produção ficcional inglesa como naquela factual o esforço por produzir programas inovadores, sejam séries, reportagens ou documentários, estes últimos uma das marcas de tal produção. Para além da percepção de que o formato reality tv diz respeito a "pessoas reais fazendo coisas reais em lugares reais", da pré-produção até a pós-produção, incluindo filmagem, edição e finalização, o documentário televisivo "Make Bradford British" buscou agregar elementos ficcionais e jornalísticos em sua realização. Para o diretor, a separação entre reality shows e documentários televisivos, bem como aquela entre sensacionalismo e humanização, ou entre fabulação e jornalismo, não pode ser facilmente estabelecida, já que todos esses gêneros tornam-se cada vez mais hibridizados e visam, ainda que de maneiras distintas, contar histórias por meio da criação de personagens em interação. Na perspectiva do diretor, seriam eles os que estabelecem demarcações entre os gêneros, já que se tornam mais autênticos à medida que são criados pelos próprios sujeitos, e não a partir de imposições do realizador, a exemplo do que vemos em documentários que deslizam entre uma ou outra posição autoral: aquela mais exterior, voltada para a construção dos personagens, ou aquela mais subjetiva, realizada a partir deles.

De certo modo, um dos aspectos mais relevantes foi a percepção de que mais do que separar uma produção televisiva ficcional de uma factual, 
podemos identificar elementos constituintes da ficcionalidade ou da factualidade de um programa em diferentes graus. Mais do que isso, cabe ao espectador decifrar, em sua "leitura", a ênfase em um ou outro desses elementos, como propõe Odin ao tratar da "leitura ficcionalizante" e da "leitura documentarizante" de obras audiovisuais (Odin, 2012: 14). No caso de "Make Bradford British", há uma clara tendência de aproximação à linguagem dos documentários no modo de articulação narrativa, como se pudéssemos reconhecer a aglutinação de elementos não evidentes em documentários tradicionais mas presentes em novos documentários, propondo um possível formato de reality documentary, ou mesmo uma espécie de documentário seriado.

Se pensarmos na relação entre reportagens e documentários, a partir da observação da produção inglesa veremos que ocorre a emergência de um novo formato em termos de produção de filmes e séries, enquanto o jornalismo ainda se mantém 'fechado em modelos mais convencionais. De certo modo, tal descoberta vai ao encontro das hipóteses iniciais, e também de conclusões obtidas em pesquisas anteriores, no que diz respeito aos estigmas sociais em termos de seu reforço ou transformação. Em relação a essa questão, ainda que haja um grande volume de produções televisivas que não colocam essa preocupação em primeiro plano, confirmamos uma tendência já observada no caso da televisão brasileira: a forte presença de temas polêmicos, geralmente de cunho social, chamando ao posicionamento e ao engajamento não apenas de produtores, mas também da audiência.

Em "Make Bradford British", a questão dos estigmas se coloca em evidência, a começar pelo elemento aglutinador do documentário: a temática do multiculturalismo, da imigração e das formas de convívio. Como dissemos, os episódios mostram os participantes convivendo nas casas uns dos outros e divididos em duplas formadas por sujeitos que, a 
princípio, possuem diferenças inconciliáveis entre $\mathrm{si}^{12}$. É assim que vemos um típico garoto inglês de origem operária ser inserido na família de um muçulmano; a mulher muçulmana colocada no cotidiano de uma negra inglesa que trabalha em um bar; a senhora idosa convivendo com uma jovem, e assim por diante.

Seja em termos étnicos, religiosos, geracionais, as diferenças entre cada um - e os modos de lidar com elas - colocam-se como definidoras do documentário. Ou seja, uma vez mais, a questão do convívio e do conflito entre cada um e todos (o outro próximo e o outro distante) aparece como preponderante e configura, assim, uma aproximação aos estigmas sociais. No caso do programa, isso ocorre de modo transgressor, já que aprender a lidar com as diferenças, por meio da subversão da pergunta sobre se há algo que possa definir a "britanicidade" de um cidadão do Reino Unido, é justamente seu objetivo. País de longa história no que diz respeito à presença de imigrantes - sejam eles de origem negra, árabe ou indiana, de ex-colônias ou outros lugares, entre eles o Brasil -, a premência dessa questão salta aos olhos quando nos deparamos com os desafios encenados no documentário televisivo, que deriva seu aspecto realista não apenas na definição de um formato, mas na problemática tratada.

Em termos dos personagens, uma vez mais confirmamos o modo como o documentário desmobiliza lugares comuns: ao revezar entre realizador e audiência o espaço de construção narrativa, movimento esse contemplado na produção de reality shows, os personagens não são simplesmente encaixados na história - como muitas vezes acontece no

\footnotetext{
${ }^{12}$ É interessante observar que o diretor brasileiro Cao Guimarães, no filme Rua de mão dupla (2002), utiliza um dispositivo semelhante como estratégia para a realização de um documentário, colocando em contato pessoas que antes não se conheciam e formando duplas que, transformadas em personagens, deveriam trocar de casa durante 24 horas. Munidos de câmeras de vídeo e com liberdade para filmar o que quisessem, cada participante tentou elaborar uma "imagem mental" do outro morador, sendo posteriormente entrevistados pelo diretor para relatar suas impressões sobre como teriam imaginado esse "outro" desconhecido e delas distinto.

Disponível em: http://www.caoguimaraes.com/obra/rua-de-mao-dupla/.
} 
jornalismo - mas colaboram com sua narração, determinando e sendo determinados por ela. É nesse ponto que a mistura entre realidade e ficção pode ser apontada, pois o aspecto de fabulação advindo dessa escolha - ao mesmo tempo estética e politica - corrobora a aposta factual do formato documental do programa, e é dessa síntese que vemos delinear-se o gênero da "telerrealidade", percebida como um lugar próprio da linguagem televisiva contemporânea que coloca em operação a triangulação entre autor, leitor e texto (nos termos de Eco, 1994; Iser, 2013), ou entre realizador, público e programa.

Uma espécie de factual entertainment, como colocado pelo diretor, faz-se presente nesses formatos híbridos, propondo novos modos de produzir, assistir e refletir sobre a televisão. Bhatti aponta que o documentário, especialmente o televisivo, não se encontra tão distante dos formatos de entretenimento como desejaríamos e, desse modo, programas televisivos como "Make Bradford British" podem tratar de temas relevantes e densos por meio de uma abordagem mais lúdica e emocional e, ainda assim, problematizar estigmas sociais relacionados a questões de identidade, alteridade e representação social. Não se trata, portanto, de simplesmente classificar diferentes programas mas, ao contrário disso, reconhecer um conjunto deles que possa integrar esse lugar híbrido que desliza entre formas documentais diversas, sejam elas referenciais, convencionais ou popularescas. É desse modo que a realidade passa a ser intertextualmente encenada, por meio de documentários, reportagens, séries e reality shows, complexificando os novos realismos presentes na televisão e no cinema.

Finalmente, um último aspecto merece ser apontado no estabelecimento da relação entre documentários, reportagens e realities. De acordo com Bhatti e em consonância com análises anteriormente realizadas (cf. Soares; Limberto, 2014), percebemos nas várias possibilidades factuais da programação televisiva a importância da relação entre realizador e entrevistado. Se baseada na reciprocidade, nos termos em que o filósofo 
Buber (2001) utiliza este conceito, é um pacto de confiança - e de fidúcia que se estabelece entre ambos. É dessa maneira que a relação aparentemente dual entre realizador e entrevistado se torna uma relação triádica entre realizador, entrevistado e personagem e, posteriormente, destes com o espectador.

Nesse ponto as diferenças entre a produção audiovisual brasileira e a britânica se colocam como prementes, justamente devido às características singulares de cada uma e à forte presença, no caso da produção inglesa, de formatos híbridos em termos narrativos e estéticos, e de documentários televisivos (gênero ainda pouco presente na televisão brasileira, que ainda se pauta, como notamos, por divisões mais rígidas de formatos). Além da hibridização em termos de gêneros televisivos, na produção inglesa isso se reflete no modo de demarcação dos estigmas, que se tornam mais diluídos e, portanto, potencialmente mais transformadores, levando a uma baixa frequência de redundâncias e aumentando as ressonâncias de suas imagens, mesmo que polêmicas.

Os estigmas sociais presentes nas formas audiovisuais, as politicas de representação e os regimes de visibilidade a eles relacionados se fazem na tensão entre esses sujeitos, empíricos e discursivos, colocados em cena e em tela. Mais do que reproduzir imagens de minorias ou de grupos sociais, trata-se da apresentação de diferentes culturas, construindo novas realidades. Ainda que os limites da representação sejam dados pela impossibilidade de tudo representar ou pela irredutibilidade de um outro desde sempre não-representável, quando tratamos de estigmas podemos notar certos deslocamentos nos intervalos entre ausência/presença, invisibilidade/visibilidade. Nos interstícios entre os ditos, inclusão e protagonismo deslizam possibilidades de dar a ver o outro e a ele responder, demarcando distintos posicionamentos discursivos e, consequentemente, outros modos de representação da alteridade. 
É interessante confirmar que, em relação aos estigmas, podemos acompanhar alguns temas recorrentes - como se uma dinâmica regular (repetição e diferença) acompanhasse tais tematizações. Entre eles, questões agrárias e/ou urbanas, questões de gênero, assuntos relativos ao movimento negro ou questões raciais, o mundo árabe (incluindo supostas ações terroristas a ele associadas), o tráfico de drogas e, sobretudo nas mídias audiovisuais, questões relacionadas à violência, imigração, pobreza e exclusão social, retratando em suas imagens sujeitos em situação de risco ou vulnerabilidade. Em termos de tendências, retomamos a observação de que um tema específico tem se sobressaído nas pesquisas em comunicação apoiado, sobretudo, pelos estudos culturais ou pós-coloniais e pela psicanálise: as complexas relações envolvendo a dinâmica social do convívio entre cada um e os outros, e os conflitos daí decorrentes, inseparáveis da própria sociedade em que estão inseridos. As chamadas figuras de alteridade, como dissemos, presentes nos discursos midiáticos sinalizam, de maneira privilegiada, pontos de confluência e de demarcação dos estigmas sociais.

É sempre em relação a um outro, diferente de nós (e supostamente inferiorizado na dinâmica social), que os estigmas se articulam e apontam suas especificidades, respondendo a uma questão que acompanha, insistentemente, a produção audiovisual: como, afinal, dar a ver o "outro" e estabelecer políticas para representá-lo? Se tomarmos os processos comunicacionais como uma permanente negociação, entendemos que as mídias podem ser vistas como lugares de reconhecimento e trânsito simbólico, como zonas de fronteira e passagem nas quais as reapropriações se fazem nas bordas dos contratos discursivos estabelecidos, transformando os modos de construção da representação, especialmente quando tratamos dos espaços de visibilidade e invisibilidade nelas articulados. 


\section{Referências bibliográficas}

BADIOU, A. (2002), Pequeno manual de inestética, São Paulo: Estação Liberdade.

BARTHES, R. (1998), “O efeito de real” in O rumor da língua, São Paulo: Brasiliense.

BUBER, M. (2001), Eu e tu, São Paulo: Centauro.

CHARAUdeaU, P. (2006), Discurso das mídias, São Paulo: Contexto.

COUTINHO, E.; XAVIER, I.; FURTADO, J. (2014), “O sujeito (extra) ordinário" in MOURÃO, M. D. \& LABAKI, A. (orgs.), O cinema do real, São Paulo: Cosac Naify.

ECO, U. (1994), Seis passeios pelos bosques da ficção, São Paulo: Companhia das Letras.

FIGUEIREDO, V. L. F. (2012), “A partilha do espaço urbano e a questão do outro próximo: repercussões no discurso teórico e na ficção cinematográfica" in Revista Galáxia, São Paulo, n. 24.

FOSTER, H. (1999), The return of the real, Cambridge: MIT.

GAY, P. (2010), Represálias selvagens. Realidade e ficção na literatura de Charles Dickens, Gustave Flaubert e Thomas Mann, São Paulo: Companhia das Letras.

GEERTZ, C. (2005), Obras e vidas. O antropólogo como autor, $2^{\mathrm{a}}$ Ed., Rio de Janeiro: UFRJ.

HALL, S. (2000), Identidade cultural na pós-modernidade, Rio de Janeiro: DP\&A.

ISER, W. (2013), O fictício e o imaginário: perspectivas de uma antropologia literária, $2^{\mathrm{a}}$ Ed., Rio de Janeiro: Eduerj.

KAVKA. M. (2012), Reality TV - Television genres, Edinburgh: Edinburgh University Press.

MACHADO, A. \& VÉLEZ, M. L. (2009), "Persistência da reality $t v "$ in Revista Significação, São Paulo, n. 32. 
NICHOLS, B. (1991), Representing reality, Bloomington/Indianapolis: Indiana University Press.

ODIN, R. (2012), "Filme documentário, leitura documentarizante" in Revista Significação, São Paulo, Ano 39, n. 37.

PRADO, J. L. A. (ed.) (2008), A invenção do Mesmo e do Outro na mídia semanal, DVD, São Paulo: PUC-SP/CNPq. (2012), "Política da imagem na era da convocação" in Revista Significação, São Paulo, Ano 39, n. 37.

RANCIÈRE, J. (1996), O desentendimento: política e filosofia, São Paulo: Editora 34. (2005), A partilha do sensível, São Paulo: Editora 34.

SOARES, R. L. \& LIMBERTO, A. L. (2014), “Tramas do outro nas telas do discurso: circulação audiovisual e consumo cultural" in PragMatizes - Revista Latino-Americana de Estudos em Cultura, Rio de Janeiro, Ano 4, n. 6.

SOARES, R. L. \& FREIRE, M. (2013), "História e narrativas audiovisuais: de fato e de ficção" in Revista Comunicação, Mídia e Consumo, São Paulo, V. 10, n. 28.

WINSTON, B. (2005), “A maldição do 'jornalístico' na era digital” in MOURÃO, M. D. \& LABAKI, A. (orgs.), O cinema do real, São Paulo: Cosac Naify.

WHITE, H. (1994), Trópicos do discurso, São Paulo: Edusp.

XAVIER, I. (1984), O discurso cinematográfico, Rio de Janeiro: Paz e Terra.

ZIZEK, S. (2002), Bem-vindo ao deserto do real, São Paulo: Boitempo. 